\title{
Secondhand Smoke Exposure in Public Places and Support for Smoke-Free Laws in Japan: Findings from the 2018 ITC Japan Survey
}

\author{
Genevieve Sansone ${ }^{1, *}$, Geoffrey T. Fong ${ }^{1,2,3}{ }^{\oplus}$, Gang Meng ${ }^{1}$, Lorraine V. Craig ${ }^{1}$, Steve S. Xu ${ }^{1}$, \\ Anne C. K. Quah ${ }^{1}{ }^{1}$, Janine Ouimet ${ }^{1}$, Yumiko Mochizuki ${ }^{4}$, Itsuro Yoshimi ${ }^{5}$ \\ and Takahiro Tabuchi ${ }^{6}$ (D) \\ 1 Department of Psychology, University of Waterloo, 200 University Ave W., Waterloo, ON N2L 3G1, Canada; \\ gfong@uwaterloo.ca (G.T.F.); gmeng@uwaterloo.ca (G.M.); lvcraig@uwaterloo.ca (L.V.C.); \\ s4xu@uwaterloo.ca (S.S.X.); ackquah@uwaterloo.ca (A.C.K.Q.); j2ouimet@uwaterloo.ca (J.O.) \\ 2 Ontario Institute for Cancer Research, 661 University Ave Suite 510, Toronto, ON M5G 0A3, Canada \\ 3 School of Public Health and Health Systems, University of Waterloo, 200 University Ave W., \\ Waterloo, ON N2L 3G1, Canada \\ 4 Japan Cancer Society, 13th Floor, Yurakucho Center Bldg. 2-5-1, Yurakucho, Chiyoda-ku, \\ Tokyo 100-0006, Japan; mochizuki@jcancer.jp \\ 5 Division of Tobacco Policy Research, National Cancer Center Japan, 5-1-1 Tsukiji, Chuo-ku, \\ Tokyo 104-0045, Japan; iyoshimi@ncc.go.jp \\ 6 Cancer Control Center, Osaka International Cancer Institute, Chome-1-69 Otemae, Chuo Ward, \\ Osaka 541-8567, Japan; tabuchitak@gmail.com \\ * Correspondence: gsansone@uwaterloo.ca
}

Received: 9 December 2019; Accepted: 1 February 2020; Published: 4 February 2020

\begin{abstract}
Comprehensive smoke-free policies such as those called for by the WHO FCTC are the only way to protect the public effectively from the harms of secondhand smoke (SHS), yet Japan has been slow to implement this important health measure. This study examines baseline levels of smoking and SHS exposure in public places and support for smoking bans in Japan prior to the implementation of the 2018 national smoke-free law. Data are from the International Tobacco Control (ITC) Japan Wave 1 Survey (Feb-Mar 2018), a web survey of adult cigarette smokers, heated tobacco product users, dual users, and non-users (total $N=4684$ ). Measures included prevalence of smoking (whether respondents noticed people smoking inside restaurants and bars at their last visit, and workplaces in the last month), and support for complete smoking bans in these venues. Smoking prevalence in each venue was high overall in 2018 ( $49 \%$ of workplaces, $55 \%$ of restaurants, and $83 \%$ of bars), even higher than in China, the country with the greatest toll of SHS. Support for complete smoking bans was very high overall ( $81 \%$ for workplaces, $78 \%$ for restaurants, and $65 \%$ for bars). Non-users were less likely to be exposed to SHS and had higher support for smoking bans than tobacco users. These findings point to the ineffectiveness of partial smoke-free laws in Japan and reinforce the call for comprehensive smoke-free laws, which even smokers would support at higher levels than in many other ITC countries.
\end{abstract}

Keywords: Japan; smoke-free laws; tobacco control policies; smoking; support

\section{Introduction}

Secondhand smoke (SHS) is a significant threat to health, estimated to have killed 1.22 million people globally in 2017 [1]. There is no safe level of exposure to SHS. Only comprehensive smoking bans (i.e., those that cover $100 \%$ of all indoor public spaces as called for by the World Health Organization 
Framework Convention on Tobacco Control (WHO FCTC)) are effective in protecting the public from the harms of tobacco smoke [2]. In contrast, partial smoking bans (i.e., those that do not cover all public venues or include allowances for designated smoking areas) are not effective [2,3]. The introduction of national legislative smoking bans is known to lead to improved population health outcomes through reduced exposure to SHS, yet 78\% of the world's population were still not protected by comprehensive smoke-free laws in 2018 [4,5]. The struggle to pass comprehensive smoke-free laws to reduce the massive health threat of SHS continues throughout the world, and this is exemplified in the continuing weak and slow progress toward this important health measure in Japan [6].

Rates of cigarette smoking have declined in Japan in recent years to $18 \%$ of adults $(30 \%$ men, $8 \%$ women) in 2015, and are lower than in other Asian countries such as the Republic of Korea and China $[7,8]$. However, Japan lags behind in the implementation of strong smoke-free laws to protect the public from exposure to tobacco smoke. The 2017 WHO Global Progress Report ranked Japan at the lowest level for smoke-free policy implementation [7]. This lack of smoke-free progress is largely due to the political and social climate in the country, where the tobacco industry has long had a strong presence and influence over government and educational campaigns, contributing to continued social acceptability of smoking [6,9-11]. As a result, SHS exposure and its associated harms remain a significant public health challenge. It is estimated that 15,000 non-smokers die each year in Japan from exposure to SHS, and smoking was the leading risk factor for mortality in men in $2015[12,13]$.

Japan ratified the WHO FCTC in 2004, but prior to 2018, there was no national smoke-free law. Only two prefectures (Kanagawa in 2010 and Hyogo in 2013) and one city (Bibai in 2016) had implemented their own smoking bans, although these were not comprehensive and lacked strong enforcement $[8,9]$. Previous legislation under the 2003 Health Promotion Act and Workplace Smoke-free Guidelines encouraged managers of public places and workplaces to take any necessary steps to prevent exposure to SHS, but allowed for designated smoking rooms and did not specify any penalties for failing to restrict smoking [14-16].

In light of the upcoming Summer Olympics and Paralympic Games being held in Tokyo from 24 July to 9 August, 2020 (Tokyo 2020), the Health Ministry has taken steps to strengthen smoke-free regulations in Japan. An amendment to the Health Promotion Act banning smoking in all public places was proposed in 2016, but was rejected in 2017 after powerful opposition from the tobacco industry [9]. A weaker version of the law was then passed in July 2018 and will take effect in stages to allow time for compliance, starting 1 July, 2019 and ending with full enforcement by 1 April, 2020 prior to Tokyo 2020 [17]. The amended Act bans all forms of smoking in certain indoor public places, such as schools, hospitals, and government offices starting in July 2019, but allows outdoor smoking areas on the premises (with the condition that necessary measures to prevent SHS exposure among non-smokers must be taken). Indoor smoking will also be banned in restaurants and bars when the law takes full effect, but designated smoking rooms will be allowed, rendering the law to be less than comprehensive. In addition, existing small venues (less than 100 square meters) are currently exempt from the law; thus fewer than half of restaurants and bars will actually be covered by the ban $[18,19]$.

In contrast, the Tokyo Metropolitan Government passed its own smoke-free legislation in 2018, which will take effect in April 2020 and is expected to cover $80 \%$ of restaurants $[19,20]$. Although still not comprehensive, Tokyo's law is stronger than the national law.

The new regulations of the amended Health Promotion Act have also been extended to include heated tobacco products (HTPs) such as IQOS, glo, and Ploom TECH, which are battery-powered heating devices that heat tobacco rather than burning it, and which have become increasingly popular among smokers in Japan in recent years. Like cigarette smoking, HTP use will be permitted in designated smoking rooms within new or large-scale eating and drinking establishments only accessible to those aged 20 and older and with signs indicating that smoking is allowed. But unlike cigarette smoking rooms, which are to be used exclusively by smokers without eating or drinking, HTPs will be permitted in areas where people are eating and drinking [20-22]. 
Few jurisdictions in Japan have implemented smoke-free regulations, and the few studies evaluating the effectiveness of smoke-free regulations in Japan have focused on workplaces [16,23,24]. For example, survey data from 2011 and 2012 has shown that complete smoking bans in Japanese workplaces were associated with lower prevalence of current smoking, lower levels of self-reported discomfort or ill health due to SHS, and lower SHS exposure compared to workplaces with partial or no bans $[23,24]$.

Given the variation in smoke-free policy implementation across venues, jurisdictions, and types of tobacco products in Japan thus far, and the upcoming changes to smoke-free laws, more research is needed to evaluate existing smoke-free policies in public places and develop evidence-based recommendations for more effective smoke-free laws.

The present study was designed: (1) to measure current prevalence of smoking in public places (workplaces, restaurants, and bars) as reported by large, representative samples of adult cigarette smokers, HTP users, and non-smokers at their last visit, and (2) to assess the level of support among Japanese smokers and non-smokers for comprehensive smoke-free laws. These findings aim to complement recent data comparing the rates of HTP use and cigarette smoking in public places in Japan in 2018 [25], and follows the same design as previous studies evaluating the impact of smoke-free policies in other countries such as China [26]. This study was conducted in 2018, prior to the implementation of the amended Health Promotion Act. We examined differences between respondent type (particularly smokers vs. non-smokers) on both sets of measures, and we compared Japan to other countries - those that have implemented comprehensive laws and those that have partial smoke-free laws.

\section{Materials and Methods}

\subsection{Data Source and Sampling Design}

Data are from the International Tobacco Control (ITC) Japan Wave 1 Survey, a web survey of approximately 4500 adults aged 20 and older across 8 geographic regions of the country, who were recruited by email from Rakuten Insight's Japan web panel. The surveys were conducted from 3 February to 2 March 2018, and closed once the quotas for tobacco users and non-users were achieved. The response rate for the Wave 1 Survey was $45.1 \%$. All respondents gave informed consent before participating in the study, and the survey methods and materials were approved by the University of Waterloo Office of Research Ethics (ORE \#31428). The Wave 1 Survey sample was designed to be representative of adult cigarette smokers, HTP users, dual users, and non-users within each region. Table 1 shows the breakdown of the full sample by user type and sample sizes used in this paper. Note that in this study, "smokers" refers to those who smoke cigarettes (either cigarettes only, or dual users of cigarettes and HTPs; excluding HTP only users). Smokeless tobacco product users were not included in the study. For a more detailed description of the ITC Japan Survey methods, see the technical report at the following website: https://itcproject.org/files/JP1-1.5_Technical_Report_28Feb2019_FINAL.pdf/ technical-report/.

Table 1. Study sample.

\begin{tabular}{clcc}
\hline User Type & \multicolumn{1}{c}{ Definition } & Percent \\
\hline Cigarette & Smokes cigarettes at least monthly and uses HTPs less than weekly or not at all & 3306 & $70.6 \%$ \\
smokers & Uses HTPs at least weekly and smokes cigarettes less than monthly or not at all & 207 & $4.4 \%$ \\
HTP users & Smokes cigarettes at least monthly AND uses HTPs at least weekly & 555 & $11.8 \%$ \\
Dual users & Smokes cigarettes less than monthly or not at all AND uses HTPs less than & 616 & $13.2 \%$ \\
Non-users & weekly or not at all & 4684 & $100 \%$ \\
Total & & & \\
\hline
\end{tabular}




\subsection{Measures}

The prevalence of smoking and SHS exposure in public places was measured by asking all respondents whether they noticed people smoking inside: (a) restaurants, (b) bars, and (c) workplaces, and results are shown for "yes" responses (Note: the question asked about 'smoking' in general, but was in the cigarette smoking section of the survey, so results are interpreted as referring to cigarette smoking.). Specifically, for workplaces, those who worked indoors were asked whether people smoked in their workplace in the last month. For restaurants and bars, those who said they had visited a restaurant/bar in their city in the last six months were asked whether people were smoking inside at their last visit.

Support for smoke-free policies was measured by asking respondents whether they support or oppose a total ban on smoking cigarettes in: (a) restaurants, (b) bars, and (c) workplaces, and (d) whether they support a ban on smoking at the 2020 Tokyo Olympics. For each question, results are shown for responses of "support" and "strongly support" combined (vs. "oppose", "strongly oppose", or "don't know").

\subsection{Data Analysis}

All analyses were conducted in SAS with SUDAAN V11 using the multilog procedure (Research Triangle Institute, Research Triangle Park, NC, USA). All results were adjusted for demographic variables (sex and age group). Analytical cross-sectional survey weights were used to account for the complex sampling design for all the analyses to make respondents within each of the user subgroups representative of the corresponding population with respect to demographics and region.

\section{Results}

\subsection{Smoking Prevalence and SHS Exposure in Public Places}

As shown in Figure 1, smoking prevalence in public places in Japan was high overall. Almost half of workplaces (49\%) had people smoking inside in the last month; over half of restaurants $(55 \%)$, and $83 \%$ of bars had smoking the last time respondents visited these places. Because the cross-sectional weights were calibrated to the population numbers of each of the mutually exclusive user groups, crossed with the 8 geographical regions of Japan, sex, and 4 age groups of the population of Japan aged 20 years and above, these weighted percentages of observed smoking can be taken to be national estimates of smoking prevalence in each of the three venues in Japan.

Results were fairly consistent across user categories, with no significant differences in workplace SHS exposure. For restaurants and bars, cigarette smokers and dual users were each more likely to be exposed than non-users ( $p<0.05$ for each comparison, except for dual vs. non-users in bars, $p<0.01$ ). HTP users were also more likely to be exposed in bars than non-users ( $91 \%$ vs. $82 \%, p<0.05)$, but not in restaurants.

\subsection{Support for Smoke-Free Policies}

Overall support for complete smoking bans in public places was high in Japan in 2018-over three-quarters of respondents supported a total ban on smoking cigarettes in restaurants $(78 \%)$ and workplaces $(81 \%)$ and two-thirds supported a ban in bars (65\%) (see Figure 2). Support for smoke-free Olympics was also high overall (74\%). Across the user groups, support was significantly higher among non-users than any other user group, for each venue ( $p<0.01$ for each comparison). Other differences included higher support for smoke-free workplaces and Olympics among HTP users than cigarette smokers ( $p<0.01$ and $p<0.05$, respectively), and higher support for smoke-free bars among dual than HTP users ( $30 \%$ vs. $24 \%, p<0.001)$. 


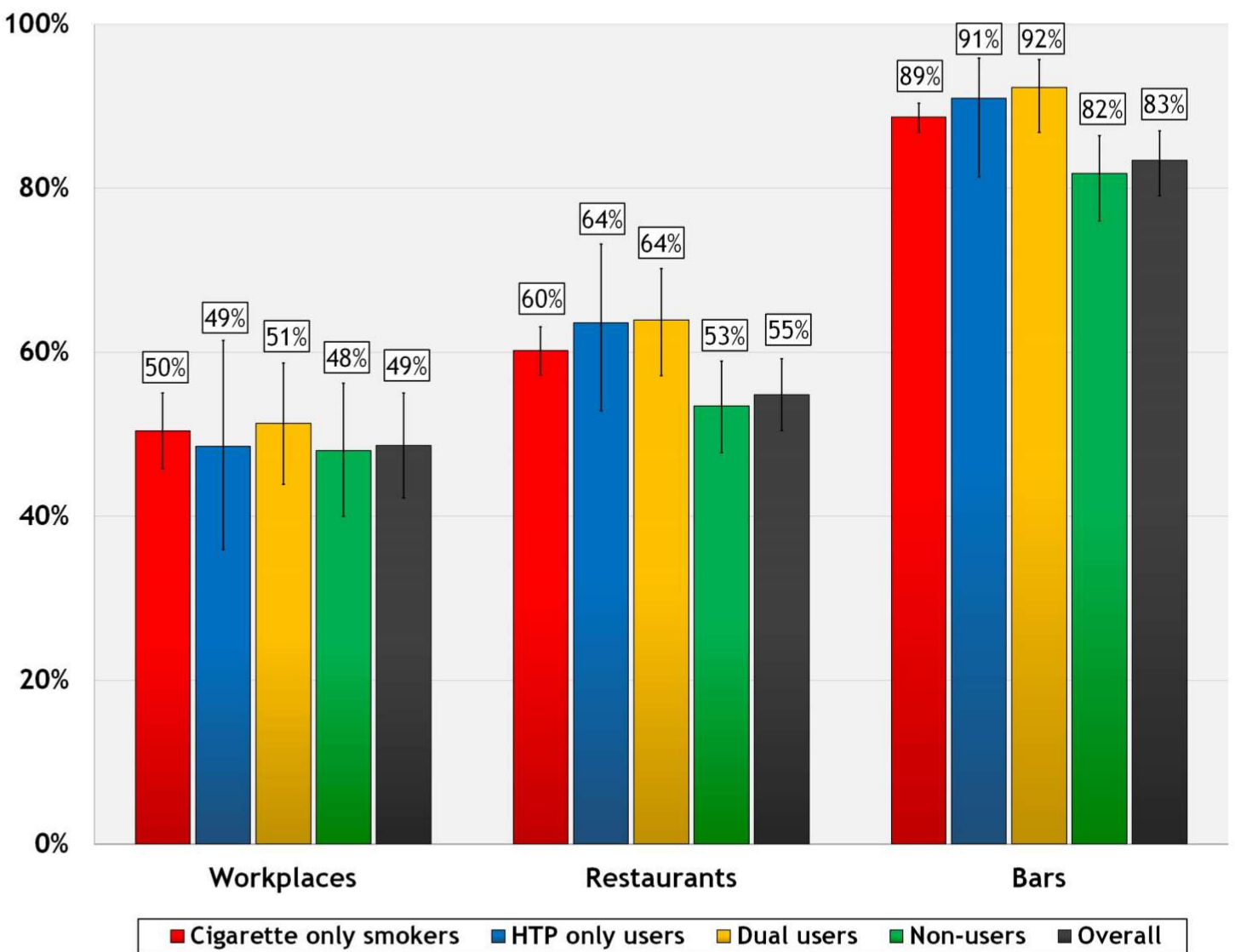

Figure 1. Prevalence of smoking in workplaces, restaurants, and bars, by user group.

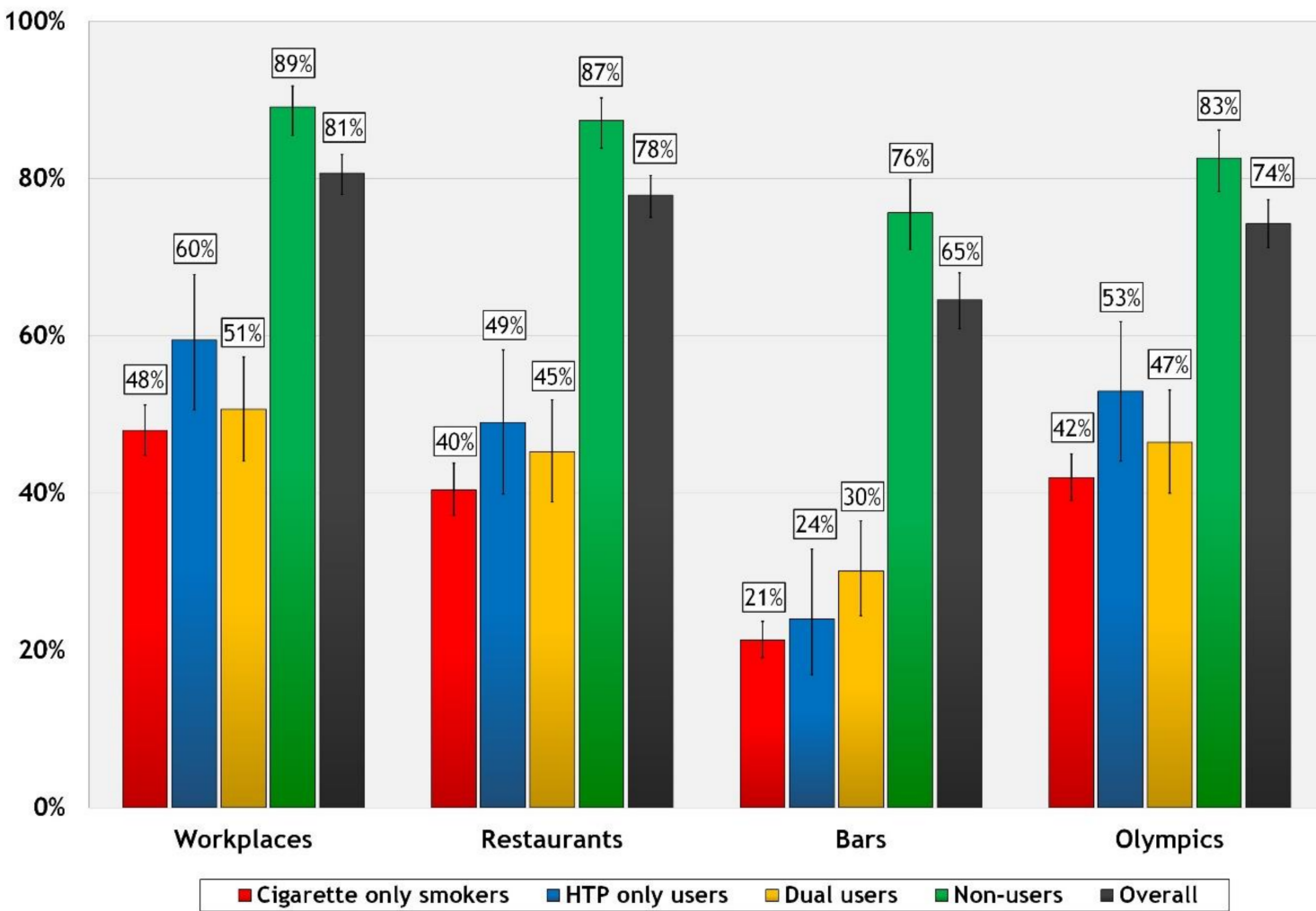

Figure 2. Percentage of respondents who support or strongly support complete smoking bans in workplaces, restaurants, bars, and at Tokyo 2020, by user group. 


\section{Discussion}

\subsection{Summary of Findings}

This study shows that the lack of strong smoke-free laws in Japan has led to extremely high rates of exposure to deadly SHS in public places. The findings demonstrate not only that Japan needs to implement a comprehensive smoke-free law without exceptions, but also that the Japanese public-including many smokers themselves-are supportive of such a law.

Evidence from Japan and many other countries shows that partial smoking bans are not effective [2,3]; however, previous research has found that the majority of restaurants and bars in Japan in 2018 still allowed smoking in some areas, in accordance with the existing allowances under national legislation [25]. As a result, this study found that smoking and SHS exposure in these venues was very high-especially for bars. Approximately half of all workplaces (49\%) and restaurants (55\%) and over three-quarters of bars (83\%) had smoking in 2018. Another important finding from this study is that overall, the majority of the Japanese public agree that cigarette smoking should be completely banned in public places. As expected, support for complete smoking bans was lowest among cigarette smokers and much higher among non-users, and non-users were also less likely to be exposed to SHS in public places than tobacco users. However, there were few differences between types of tobacco users (cigarettes, HTP, and dual users) on each of the outcome variables.

\subsection{Comparison with Other Studies}

There is little previous data on SHS exposure in Japan, but data from 2010 showed that exposure at work among adults ( $46 \%$ of men and $18 \%$ of women) was similar to the current findings [8]. This suggests that there has been no improvement in recent years in SHS exposure in workplaces, owing to the lack of smoke-free laws implemented during this time. Our findings on SHS exposure are also consistent with existing data from the ITC Japan 2018 Survey which shows the high rates of reported cigarette smoking in public places, in comparison to HTP use [25].

Comparisons with other ITC Asian countries with a high burden of tobacco use show the need for stronger global efforts to reduce tobacco use and SHS exposure. ITC cross-country comparisons using identical survey measures of smoke-free policy evaluation suggest that smoking prevalence in public places in Japan in the current study may be as high or higher than in other Asian countries before the implementation of smoke-free laws [27]. For example, the overall prevalence of smoking in restaurants was 55\% in Japan in 2018, compared to 59\% in China in 2013-2015 (as reported by both smokers and non-smokers in five cities)—where no national smoke-free laws were in place [26]. Smoking was even more prevalent in workplaces and in bars in Japan (49\% and $83 \%$ overall, respectively) than in China (44\% and $79 \%$ overall in cities). In contrast, in countries where comprehensive smoking bans in line with WHO FCTC Article 8 have been implemented, smoking prevalence in public places has been dramatically reduced or nearly eliminated. For example, after smoke-free laws in Ireland (2004) and France (2008), smoking in restaurants decreased from over $70 \%$ to less than $5 \%$, which was maintained in the long term [28-30].

ITC Project data also shows that support for smoke-free policies is higher overall in Japan than in other countries. For example, the percentage of Japanese cigarette-only smokers who support smoke-free bars $(21 \%)$ is higher than the percentage of smokers in Ireland (12\%) and France (14\%) before those countries implemented their national smoke-free laws [27]. The overall level of public support in Japan is also much higher than the overall level found among smokers and non-smokers in China on the same measures (e.g., $65 \%$ of all respondents in Japan vs. $41 \%$ of all respondents in Chinese cities support smoke-free bars) [26]. Support for smoke-free laws in 2018 is also greater than the level of support found in earlier studies in Japan. For example, survey data from 2007 showed that only $4 \%$ of smokers and 35\% of non-smokers supported a complete smoking ban in workplaces; and that the majority of the Japanese public supported partial smoking bans over complete bans [8]. The findings from the current study suggest that support for smoke-free laws may have increased in recent years 
in Japan, and data from the ITC Project has also shown that public support for smoke-free laws tends to increase even further after they are implemented in a country-especially for comprehensive laws [31-33].

\subsection{Strengths and Limitations}

This study is the first national evaluation of Japan's lack of comprehensive smoke-free laws on smoking prevalence in public places and support for such laws among a large, nationally representative sample of cigarette smokers, HTP users, and non-users. While previously published data has also reported on rates of cigarette smoking in indoor public places by smokers themselves [25], this study includes data from both tobacco users and non-users to measure overall national estimates for the prevalence of observed smoking and SHS exposure. This same method for estimating overall prevalence has also been used in other ITC studies where non-users were sampled [26]. However, as this is a baseline cross-sectional study, causal inferences about the impact of smoke-free laws (or the lack thereof) cannot be made. An additional limitation in this study is the use of self-report measures which were not validated and may be subject to recall bias; however, these same measures have been used in many other published studies to evaluate smoke-free policies, including over 50 studies published from ITC Project data across over 20 countries [3,26,29,34,35]. Further research with additional waves of the ITC Japan Survey will be conducted to evaluate the more extensive smoke-free laws that will be implemented in April 2020, including any differences in the impact of laws on cigarette smoking compared to HTP use in public places.

\subsection{Implications}

While the findings suggest that public support is not a barrier for smoke-free action, the influence of the tobacco industry in Japan remains an obstacle. For example, Japan Tobacco has a long history of promoting "smoking manners" to allow smokers and non-smokers to coexist in the absence of strong smoke-free laws [11]. This strategy has included various media campaigns and sponsoring the establishment of indoor/outdoor smoking areas, despite strong evidence that designated smoking areas fail to protect from the harms of SHS. This strategy is also being used in China-another country where the tobacco industry has a powerful influence over policy-making. Efforts to develop and implement a national smoke-free law in China have halted, with the focus now on the State Tobacco Monopoly Agency's movement to build a "civilized smoking environment" consisting of indoor smoking rooms across the country [36,37].

Although Japan has made recent progress with the passage of new smoke-free legislation since this study was conducted, evidence has shown that only comprehensive laws, along with strong implementation and enforcement, are effective. But even if a more comprehensive law is implemented, the rising use of HTPs in Japan and the promotion of a "smoke-free" vision by the tobacco industry may increase the challenges of enforcing the law depending on whether HTPs remain subject to the same restrictions. As a Party to the WHO FCTC, Japan should follow the recommendations of the $\mathrm{WHO}$, which has recently decided that HTPs are tobacco products and are therefore subject to the same provisions of the FCTC as cigarettes, including smoke-free policies [38].

\section{Conclusions}

This study provides baseline evidence that the lack of a comprehensive national smoke-free law in Japan prior to 2018 has resulted in an extremely high prevalence of exposure to deadly SHS in indoor public places and workplaces. A comprehensive and strongly enforced law in line with the WHO FCTC Article 8 Guidelines would achieve substantial reductions in SHS exposure and its resulting harms in Japan, as shown by evidence from other ITC countries.

While new smoke-free legislation will be implemented in Japan by April 2020, that law will still not be comprehensive. The findings of this study demonstrate that the Japanese public would be 
supportive not only of a smoke-free Olympics, but also of a complete smoking ban covering all indoor public places without exceptions.

Author Contributions: Conceptualization, G.T.F. and G.S.; data collection, Y.M., I.Y. and T.T.; project administration, J.O. and A.C.K.Q.; data analysis, G.M.; writing - original draft preparation, G.S.; visualization, G.S.; writing-review and editing, G.T.F., L.V.C., S.S.X., A.C.K.Q. and J.O. All authors have read and agreed to the published version of the manuscript.

Funding: This research was funded by a Canadian Institutes of Health Research Foundation Grant (FDN-148477), with additional support provided by a grant from the National Cancer Center and Research Development Fund (28-A-24), and a Senior Investigator Award from the Ontario Institute for Cancer Research to G.T.F.

Conflicts of Interest: G.T.F. has served as an expert witness on behalf of governments in litigation involving the tobacco industry. All other authors declare no conflict of interest. The funders had no role in the design of the study; in the collection, analyses, or interpretation of data; in the writing of the manuscript, or in the decision to publish the results.

\section{References}

1. GBD 2017 Risk Factor Collaborators. Global, regional, and national comparative risk assessment of 84 behavioural, environmental and occupational, and metabolic risks or clusters of risks for 195 countries and territories, 1990-2017: A systematic analysis for the Global Burden of Disease Study 2017. Lancet 2018, 392, 1923-1994.

2. World Health Organization. WHO Report on the Global Tobacco Epidemic, 2009: Implementing Smoke-Free Environments; World Health Organization: Geneva, Switzerland, 2009.

3. International Agency for Research on Cancer (IARC). IARC Handbooks of Cancer Prevention in Tobacco Control: Evaluating the Effectiveness of Smoke-free Policies; IARC: Lyon, France, 2009; Volume 13.

4. World Health Organization. WHO Report on the Global Tobacco Epidemic, 2019; World Health Organization: Geneva, Switzerland, 2019.

5. Frazer, K.; Callinan, J.E.; McHugh, J.; van Baarsel, S.; Clarke, A.; Doherty, K.; Kelleher, C. Legislative smoking bans for reducing harms from secondhand smoke exposure, smoking prevalence and tobacco consumption. Cochrane Database Syst. Rev. 2016, 2, CD005992. [CrossRef] [PubMed]

6. Assunta, M. Global Tobacco Industry Interference Index 2019; Global Center for Good Governance in Tobacco Control (GGTC): Bangkok, Thailand, 2019.

7. World Health Organization. WHO Report on the Global Tobacco Epidemic, 2017. Monitoring Tobacco Use and Prevention Policies; World Health Organization: Geneva, Switzerland, 2017.

8. Katanoda, K.; Jiang, Y.; Park, S.; Lim, M.K.; Qiao, Y.-L.; Inoue, M. Tobacco control challenges in East Asia: Proposals for change in the world's largest epidemic region. Tob. Control 2014, 23, 359-368. [CrossRef] [PubMed]

9. Iida, K.; Proctor, R.N. 'The industry must be inconspicuous': Japan Tobacco's corruption of science and health policy via the Smoking Research Foundation. Tob. Control 2018, 27, e3-e11. [CrossRef] [PubMed]

10. Bialous, S.A.; Mochizuki-Kobayashi, Y.; Stillman, F. Courtesy and the challenges of implementing smoke-free policies in Japan. Nicotine Tob. Res. 2006, 8, 203-216. [CrossRef] [PubMed]

11. Kashiwabara, M.; Armada, F. Mind your "smoking manners": The tobacco industry tactics to normalize smoking in Japan. Kobe J. Med. Sci. 2013, 59, 132-140.

12. Nomura, S.; Sakamoto, H.; Glenn, S.; Tsugawa, Y.; Abe, S.K.; Rahman, M.M.; Brown, J.C.; Ezoe, S.; Fitzmaurice, C.; Inokuchi, T.; et al. Population health and regional variations of disease burden in Japan, 1990-2015: A systematic subnational analysis for the Global Burden of Disease Study 2015. Lancet 2017, 390, 1521-1538. [CrossRef]

13. The Japan Times. Passive smoke kills 15,000 people a year in Japan, study finds. Available online: https://www.japantimes.co.jp/news/2016/05/31/national/science-health/passive-smoke-kills-15000people-annually-japan-health-study-finds/\#.XO1TD4hKiUl (accessed on 28 May 2019).

14. Ministry of Health Labour and Welfare. Health Promotion Act, Law No. 103; Ministry of Health: Tokyo, Japan, 2003.

15. Ministry of Health Labour and Welfare. Guidelines on Passive Smoking Prevention Measures in the Workplace; Ministry of Health: Tokyo, Japan, 2003. 
16. Tabuchi, T.; Hoshino, T.; Hama, H.; Nakata-Yamada, K.; Ito, Y.; Ioka, A.; Nakayama, T.; Miyashiro, I.; Tsukuma, H. Complete workplace indoor smoking ban and smoking behavior among male workers and female nonsmoking workers' husbands: A pseudo cohort study of Japanese public workers. Biomed. Res. Int. 2014, 2014, 303917. [CrossRef] [PubMed]

17. Umeda, S. Japan: Smoking Regulations Are Getting Stricter. Available online: https://www.loc.gov/law/ foreign-news/article/japan-smoking-regulations-are-getting-stricter/ (accessed on 2 July 2019).

18. The Japan Times. Measures against secondhand smoke insufficient. Available online: https://www.japantimes. co.jp/opinion/2018/03/19/editorials/measures-secondhand-smoke-insufficient/\#.XO1XwYhKiUm (accessed on 28 May 2019).

19. Osaki, T. Japan's watered-down smoking ban clears Diet. Available online: https://www.japantimes.co.jp/ news/2018/07/18/national/crime-legal/japans-watered-smoking-ban-clears-diet/\#.XRuYzOhKiUl (accessed on 2 July 2019).

20. Osaki, T. Tokyo lawmakers approve anti-smoking ordinance as capital gears up for 2020 Olympics. Available online: https://www.japantimes.co.jp/news/2018/06/27/national/tokyo-lawmakers-approve-anti-smokingordinance-capital-gears-2020-olympics/\#.XO1YZ4hKiUl (accessed on 28 May 2019).

21. Yumae, S. New rules in Japan take aim at heated tobacco. Available online: https://asia.nikkei.com/Business/ Business-trends/New-rules-in-Japan-take-aim-at-heated-tobacco (accessed on 28 May 2019).

22. Ministry of Health. Outline of the Act on the Partial Revision of the Health Promotion Act (No. 78 of 2018). Available online: https://www.mhlw.go.jp/english/policy/health-medical/health/dl/201904kenko.pdf (accessed on 8 July 2019).

23. Tabuchi, T.; Colwell, B. Disparity and trends in secondhand smoke exposure among Japanese employees, particularly smokers vs. non-smokers. PLoS ONE 2016, 11, e0152096. [CrossRef] [PubMed]

24. Tabuchi, T.; Hoshino, T.; Nakayama, T. Are partial workplace smoking bans as effective as complete smoking bans? A national population-based study of smoke-free policy among Japanese employees. Nicotine Tob. Res. 2016, 18, 1265-1273. [CrossRef] [PubMed]

25. Sutanto, E.; Smith, D.M.; Miller, C.; O'Connor, R.J.; Hyland, A.; Tabuchi, T.; Quah, A.C.K.; Cummings, K.M.; Xu, S.; Fong, G.T.; et al. Use of heated tobacco products within indoor spaces: Findings from the 2018 ITC Japan Survey. Int. J. Environ. Res. Public Health 2019, 16, 4862. [CrossRef] [PubMed]

26. Sansone, G.; Fong, G.T.; Yan, M.; Meng, G.; Craig, L.; Xu, S.S.; Quah, A.C.K.; Wu, C.; Feng, G.; Jiang, Y. Secondhand smoke exposure and support for smoke-free policies in cities and rural areas of China from 2009 to 2015: A population-based cohort study (the ITC China Survey). BMJ Open 2019, 9, e031891. [CrossRef] [PubMed]

27. ITC Project and Tobacco Control Office; China CDC. ITC China Project Report. Findings from the Wave 1 to 5 Surveys (2006-2015); University of Waterloo: Waterloo, ON, Canada; Tobacco Control Office, Chinese Center for Disease Conrol and Prevention: Beijing, China, 2017.

28. Fong, G.T.; Hyland, A.; Borland, R.; Hammond, D.; Hastings, G.; McNeill, A.; Anderson, S.; Cummings, K.M.; Allwright, S.; Mulcahy, M.; et al. Reductions in tobacco smoke pollution and increases in support for smoke-free public places following the implementation of comprehensive smoke-free workplace legislation in the Republic of Ireland: Findings from the ITC Ireland/UK Survey. Tob. Control 2006, 15, iii51-iii58. [CrossRef] [PubMed]

29. Fong, G.T.; Craig, L.V.; Guignard, R.; Nagelhout, G.E.; Tait, M.K.; Driezen, P.; Kennedy, R.D.; Boudreau, C.; Wilquin, J.-L.; Deutsch, A.; et al. Evaluating the effectiveness of France's indoor smoke-free law 1 year and 5 years after implementation: Findings from the ITC France Survey. PLoS ONE 2013, 8, e66692. [CrossRef] [PubMed]

30. European Commission. Special Eurobarometer Report 429: Attitudes of Europeans Towards Tobacco and Electronic Cigarettes; Directorate-General for Communication: Brussels, Belgium, 2015.

31. Mons, U.; Nagelhout, G.E.; Guignard, R.; McNeill, A.; van den Putte, B.; Willemsen, M.C.; Brenner, H.; Pötschke-Langer, M.; Breitling, L.P. Comprehensive smoke-free policies attract more support from smokers in Europe than partial policies. Eur. J. Public Health 2012, 22 (Suppl. 1), 10-16. [CrossRef] [PubMed]

32. Hyland, A.; Higbee, C.; Borland, R.; Travers, M.; Hastings, G.; Fong, G.T.; Cummings, K.M. Attitudes and beliefs about secondhand smoke and smoke-free policies in four countries: Findings from the International Tobacco Control Four Country Survey. Nicotine Tob. Res. 2009, 11, 642-649. [CrossRef] [PubMed] 
33. Thrasher, J.F.; Pérez-Hernández, R.; Swayampakala, K.; Arillo-Santillán, E.; Bottai, M. Policy support, norms, and secondhand smoke exposure before and after implementation of a comprehensive smoke-free law in Mexico City. Am. J. Public Health 2010, 100, 1789-1798. [CrossRef] [PubMed]

34. World Health Organization Western Pacific Region; ITC Project. Smoke-Free Policies in China, Evidence of Effectiveness and Implications for Action, October 2015; World Health Organization Regional Office for the Western Pacific: Manila, Philippines, 2015.

35. Fong, G.T.; Sansone, G.; Yan, M.; Craig, L.; Quah, A.C.K.; Jiang, Y. Evaluation of smoke-free policies in seven cities in China, 2007-2012. Tob. Control 2015, 24, iv14-iv20. [CrossRef] [PubMed]

36. Yu, G. It is very necessary to build a civilized smoking environment. Available online: http://www.tobaccochina. com/shidian/zaixianshidian/201812/20181217174257_777988.shtml (accessed on 14 January 2019).

37. STMA issued this guideline: Building a civilized smoking environment and helping to build a beautiful China. Available online: http://www.etmoc.com/gedi/Newslist?Id=104161 (accessed on 14 January 2019).

38. Conference of the Parties to the WHO Framework Convention on Tobacco Control. DECISION FCTC/COP8(22) Novel and Emerging Tobacco Products. Available online: https://www.who.int/fctc/ cop/sessions/cop8/FCTC_COP8(22).pdf (accessed on 15 August 2019).

(C) 2020 by the authors. Licensee MDPI, Basel, Switzerland. This article is an open access article distributed under the terms and conditions of the Creative Commons Attribution (CC BY) license (http://creativecommons.org/licenses/by/4.0/). 